\title{
Effect of functional resistance drills with Elastic bands on some of physical and biomechanical variables and kicking accuracy in soccer \\ *Dr. Hamada Abdel-Aziz Habib
}

\section{Abstract:}

It is already clear the importance of resistance training with elastic bands to improve the level of performance compared to more traditional drills. So the present study aimed to identify the effect of functional resistance drills with elastic bands on some of physical and biomechanical variables and kicking accuracy in soccer junior. Experimental method was used; (pre-test \& post-test), with a single experimental group, from fifteen soccer Junior (aged 17.54 \pm 0.7 years, body mass: $67.84 \mathrm{~kg}$, height: $171.53 \mathrm{~cm})$ constituted one experimental group. and (5) junior for pilot study ( $n=15)$, functional drills and the pretest-posttest are done during specific prep phase of training with duration 10-weeks training program for ( 3 training units per week for $2 \mathrm{hrs})$, Repetition (8-12), and (3-5) sets. after the functional resistance drills finish, biomechanical analysis was performed using motion analysis Program (win analyze) computer-assisted. It was a post-test to compared the pre-test by using statistical procedures: (Mean standard deviation - Median - Coefficient of Skewness - T-Test ), and discussion it was possible to conclude the Functional resistance training using elastic bands has improved values of the biomechanical variables under study in post-test, it is improved performance of kicking in front of the front foot on goal, as well as led to kinetic bonding between the leg joints (Hip- Knee- Ankle) in backswing and impact phases while kicking performance. Study shows that there are statistically significant differences between the mean (pre-test and post-test) measurements of the study sample, with pre-test at the level $(0.05)$ in all physical variables and accuracy and kick timing, this is confirmed by the results this study, where Static balance $(3.632 \mathrm{~s})$ Muscle strength for back extensors mean was (70 Kgf), Muscle strength for legs extensors mean was (131 Kgf), Quadrant jump test mean was $(3.166 \mathrm{~s})$, High jump from stability mean was $(76.33 \mathrm{~cm})$ Illinois agility mean was (11.530 s), Accuracy kick mean was (4.833 Deg.) and Kick timing mean was $(0.278 \mathrm{~s})$.

Key words: Functional resistance, Biomechanics, Soccer, kicking

Associate professor at Physical Education \& movement Sciences Dep. College of Education, Qassim University, and sports kinesiology Dep. Faculty of Physical Education, Mansoura University 


\section{Introduction:}

Soccer is one of the most widely played sports in the world, from a physiological point of view, soccer is a highintensity, long-lasting intermittent exercise, match is (2 round of 45-50 minutes interspersed by 15 -minute rest) that relies predominantly on aerobic energy pathways and muscular endurance. (Bernardo et, al., 2009), (2) Soccer is perhaps the most demanding of all sports. In the modern game (at any level) soccer training and conditioning is essential, during a soccer game, each player performs several dynamic movements (headers, cutting, tackling, sprints, kicks) which require a very good level of muscle strength, power and endurance (Hamada. A. Habib \& Hossam Houssine (2010) (10)

Muscular Strength plays a significant part in performance of such skills, where Soccer practice suggests that a soccer player needs to improve a level of strength, which is utilized effectively during competition. ( $\mathbf{J}$ Helgerud, et, al., 2011) (11)

Resistance training is proven to be safe and effective for adolescents when it is properly designed and supervised. Established scientific organizations recommend resistance training for young people to enhance muscular strength, prevent sport injuries, improve performance in sports and recreational activities, and affect health and lifestyle in a positive way (Christou A. e, al., 2006) (4) (Christou A. e, al., 2006) (4)

The focus of a traditional drills program is to increase the strength or endurance of a particular muscle or muscle group without regard to training movements that are related to activities of daily living or sport performance. While Functional training uses many joints and muscles of the upper and lower body during each movement (Tiana Weiss, et al. 2010). (23)

Functional resistance training defines as a mix of all two types of training; Training for strength and balance at the same time. It is also an integrated and multi-level drills (Horizontal, sagittal, vertical) (Fabio Comana, 2004). (9)

while Khaled wahed (2014) (13) is mentioning about (Vom Hofe,1995). that 
Functional resistance drills is suitable for all individuals at different levels of training and aims to improve the relationship between the muscles and the nervous system.

As functional resistance training becomes a more popular method to improve muscular fitness, and has been considered to be a better alternative than traditional resistance training for improving various measures of muscular fitness including strength, endurance, coordination and balance (Tiana Weiss, et al., 2010) (23) The functional resistance training could serve as an alternative and potentially more creative method for improving performance in young adults compared to more traditional drills and could possibly be applied to people of all ages and physical abilities. The overall data indicated that functional training can enhance muscular strength endurance and balance, which are variables usually associated with programs that involve more traditional resistance training drills. (Tiana Weiss, et al., 2010) (23) In addition, it may be possible to maintain or enhance flexibility through functional resistance training due to the nature of the drills (multi-joint with focus on full range of motion) (Tiana Weiss, et al., 2010) (23)

Elastic bands offer variable resistance throughout a range of motion and their incorporation with drills movements has long been used for rehabilitation purposes. More recently, however, elastic bands have found a niche in many strength programs because of the purported performance benefits (Wallace, BJ, et al., 2006) (25).

Functional

training programs consist of three main components:

Dave Schmitz (2003) (6) \& Michael Boyle (2004) (17) asserts that Functional training programs consist of three main components:

- Core stability: It is a few repetitions of each of the movement by moderate drills with gradual progress of performance and aims to achieve self-consistency and neuromuscular control.

- Core Strength: It is dynamic movements using external resistors in all levels of motor and aims to achieve muscle strength and motor integration. - Core Power: It is a movement characterized by producing Assiut Journal For Sport Science Arts 
power characterized by a velocity.

Kick is one of the most important skill in soccer. which It constitutes a basic element of a soccer game. It is multi joint activity which depends on various factors, such as the maximum strength and power of the muscles activated during the kick, the timing and appropriate transfer of energy between segments that participate in the kick, the speed and angle of approach of the player to the ball and utilization of the stretchshortening period characteristics by the muscles of the kicking leg Weineck, J. (1992) (24). Lees, A. (1998) (14) Opavsky, P. (1988) (26)

Study of Hamada \& Hossam (2010)indicate noticed that each force generated by the musculoskeletal system in the upper and lower body either originates, is stabilized by, or is transferred through the trunk and low torso. Given this fact, if athletes are to develop their full strength and power potential, then a significant portion of a strength \& conditioning program should focus on the abdominals/ oblique's/ low back/ legs. A good example of this are athletes who have a strong, powerful lower body, but do not reach full potential in vertical jumping due to weakness in the core part of the body. (10)

It is already clear the importance of resistance training with elastic bands to improve the level of performance compared to more traditional drills.

This study was attempting of examined the effects of training programs on soccer kick, and trying examination of how these characteristics are altered through training of practically more useful. It is here that the importance of this study as one of the experimental studies that can benefit of trainers in the field of the training junior as they enter into research treatment, that spouts the problems of training, particularly on the side of mastering and skill performance.

Since kicking is one of the skills that take place during a soccer match, so this study is concerned with studying kicking in front of the front foot as the strongest and fastest in the goal, to identify the impact of resistance training on some of the biomechanical variables and performance effectiveness of the young soccer, From the field experience of the researcher in the field of soccer, he noticed 
the lack of interest in functional resistance training in the preparation of the youth soccer, and that through theoretical readings, field studies and reference survey of many specialized studies it was clear that the majority of previous studies and research did not care enough to study such exercises especially from side of biomechanical for soccer junior

\section{Aim of research:}

The research aimed to identify the effect of functional resistance drills with elastic bands on some of physical and biomechanical variables and kicking accuracy in soccer junior.

Hypotheses of research: hypothesis of this study is that: - functional resistance drills with elastic bands positively affect physical and biomechanical variables which are study sample.

- functional resistance drills with elastic bands positively effect of kicking accuracy for soccer junior which are study sample.

\section{Methods:}

Experimental method was used; (pre-test \& posttest), with a single experimental group, from fifteen soccer Junior (aged $17.54 \pm 0.7$ years, body mass: $67.84 \mathrm{~kg}$, height: $171.53 \mathrm{~cm}$ ) constituted one experimental group. and (5) junior for pilot study $(n=15)$, Homogeneity of the research sample was done in the basic research variables (physical - skill), as shown in Table (1)

\section{Table (1)}

statistical characterization of the sample in basic and physical variables under study $(\mathbf{N}=\mathbf{1 5})$

\begin{tabular}{l|c|c|c|c|c}
\hline \hline Variables & $\begin{array}{c}\text { Unit of } \\
\text { measure }\end{array}$ & Mean & $\begin{array}{c}\text { Standard } \\
\text { Deviation }\end{array}$ & Median & $\begin{array}{c}\text { Skewness } \\
\text { coefficient }\end{array}$ \\
\hline \hline Age & $($ Year) & 17.54 & 0.57 & 17.5 & 0.976 \\
\hline Height & $(\mathrm{Cm})$ & 171.53 & 1.18 & 172.3 & -1.127 \\
\hline Weight & $(\mathrm{Kg})$ & 67.84 & 1.73 & 68.6 & -0.421 \\
\hline Static balance & $(\mathrm{Sec})$. & 2.624 & 0.178 & 2.6 & -0.084 \\
\hline $\begin{array}{l}\text { Muscle strength } \\
\text { for back extensors }\end{array}$ & $(\mathrm{Kgf})$ & 64.13 & 1.846 & 64 & 0.089 \\
\hline $\begin{array}{l}\text { Muscle strength } \\
\text { for legs extensors }\end{array}$ & $(\mathrm{Kgf})$ & 101.80 & 2.677 & 102 & 0.220 \\
\hline Quadrant jump test & $(\mathrm{Number})$ & 3.746 & 0.177 & 3.76 & -0.250 \\
\hline High jump from stability & $(\mathrm{Cm})$ & 52.66 & 2.350 & 51 & 0.538 \\
\hline Illinois agility test & $(\mathrm{sec})$. & 12.761 & 0.558 & 12.7 & 0.077 \\
\hline Accuracy kick & Degree & 3.22 & 0.284 & 3.3 & -0.101 \\
\hline \hline
\end{tabular}

Assiut Journal For Sport Science Arts 


\begin{tabular}{l|c|c|c|c|c}
\hline \hline Kick timing & (sec.) & 0.357 & 0.012 & 0.361 & -0.262 \\
\hline \hline Shown in
\end{tabular}

Shown in Table (1) that the Coefficients of Skewness for selected variables confined between ( \pm 3$)$ and this indicates that the distribution of the sample

Pilot Study:

The

researcher conducted a pilot study in 7 $8 / 1 / 2018$ for (5) a soccer junior, outside from research sample, this study aimed to test the validity of tools and devices used, including legalization of functional resistance program. according to the following steps:
- Determine the average resting pulse rate of the prospective sample.

- Determine the maximum pulse rate $=220$ - the average age of the sample.

- Calculation of pulse reserve $=$ maximum pulse rate - rest pulse.

The researcher was rationing and tuning the training program exercises, according to the characteristics of pregnancy as indicated by, Imad A. E. 2013 (8: 92) and shown in table (2).

Table (2)

Training load characteri

\begin{tabular}{c|c|c|c|c}
\hline \hline $\begin{array}{c}\text { Grades of } \\
\text { load }\end{array}$ & $\begin{array}{c}\text { Performance } \\
\text { time }\end{array}$ & $\begin{array}{c}\text { Inter- } \\
\text { convenience }\end{array}$ & Pulse raten/s s & $\begin{array}{c}\text { Load } \\
\text { intensity \% }\end{array}$ \\
\hline \hline Average & $30: 60 \mathrm{Sec}$. & $30 \mathrm{Sec}$. & $133: 150$ & $50: 74 \%$ \\
\hline High & $60: 90 \mathrm{Sec}$. & $45 \mathrm{Sec}$. & $154: 169$ & $75: 84 \%$ \\
\hline Maximum & $90: 120 \mathrm{Sec}$. & $60 \mathrm{Sec}$. & $171: 200$ & $85: 100 \%$ \\
\hline \hline
\end{tabular}

Pre-test measures:

Tests were made during the period $9-11$ January, 2018. It was assured that values of research variables are fair and unbiased before starting the experiment as shown table (1).

Anthropometric measurements:

(Height and Weight) and

physical testing, (Isometric Back and Leg Strength Test) to 
measures back and leg strength (19:209-210), (Quadrant Jump Test) to measures speed change of direction, (18:292) (Illinois Agility Test) (18:288), to test running agility, (Vertical Jump Test) to measures power (19: 304), (Standing Balance Test) to test Static Balance (18:365) appendix (1)

\section{Testing Skill :}

The researcher conducted a kicking accuracy test (Accuracy kick on goal) by kicked the static ball with maximal effort towards a target 18 yard away, perpendicular to the points penalty, this goal is divided into 9 boxes, Kick timing and maximal performance velocity was recorded using a speed video camera. appendix (1)

Movement Analysis:

biomechanical analysis

was performed using motion analysis Program (win analyze) computer-assisted, by used Panasonic Video camera (120 $\mathrm{f} / \mathrm{sec}$.) to obtain the values of the following biomechanical variables ... (Displacement Angular displacement- Angular velocity- Liner velocityAcceleration- Moment of inertia- Angular momentum) during the three stages of performance of the skill
(Maximum backswing Impact - Follow-up)

Main Study :

functional drills and the pretest-posttest are done during specific prep phase of training duration 10-weeks training program for (3 training units per week for $2 \mathrm{hrs}$ ), Repetition (8-12), and (3-5) sets. after the functional resistance drills finish.

Implementation of baseline study:

functional resistance drills by using elastic bands has been applied, during the specific preparation phase of the training program for kicking performance for soccer junior, in the period from $14 / 01 / 2013$ to $22 / 03 / 2018$ for (10) weeks by (3 training units per week for $2 \mathrm{hrs}$ ), Repetition (8-12), and (3-5) sets.

Apps of functional resistance Training using bands include:

1- Upper body drills

- Chest Press \& Single Leg Chest Press: Stand on one leg and lean forward with each arm straight in front of your chest, holding a TRX handle so that the TRX hangs diagonally. Keeping your body long and tall, bend your elbows to lower your body toward the TRX 
handles. Push yourself back up to the starting position.

- Chest Fly: Stand facing away from the anchor point. Lean forward. Hold handles with palms facing each other and arms extended slightly below shoulders. Keep the elbows slightly bent and simply open. Close the arms bringing the hands out in front of the body.

- Atomic Push Up: Assume Push-Up position with feet in TRX straps. Perform Push-Up with control, keeping back flat. Tuck knees into chest and return to start position with control.

- Back Row (low, 45 deg., \& high): Stand with your feet pointed straight ahead and draw in your navel. Bend at your waist until your chest is at a 45-degree angle to the ground. Extend your arms and let them hang in front of your body with a dumbbell in each hand.

- Deltoid Fly "W" \& Deltoid Fly" T": Find end range of "I" position with arms extended overhead and body nearly upright. Keep tension on TRX®. Step back into offset foot stance, with weight on forward leg. Lean back. Extend arms forward and shifting weight to rear leg. Pull arms directly overhead into "I" position by squeezing shoulder blades together. Body weight will shift to front leg. Keep arms straight.

- Triceps Press: Face away from anchor point. Hold handles with palms facing down and arms extended. Hands are at eye-level. Lean forward. Keep hands separated. Bend elbows until hands are behind head. Return to start position by driving hands forward until arms are straight.

- High Biceps Curl: Face anchor point. Hold handles with arms extended. Lean back. Bend elbows until hands are next to temples, with palms facing forehead. Return to start position with arms straight. Keep elbows high throughout movement.

Lower Body Drills

- Single Leg Balance Squat: Perform a single leg squat. Face anchor point with legs together and left foot lifted slightly. Hold handles with elbows bent and at sides.

- Suspended Lunge: Face away from anchor point. Place right foot into both foot cradles at once, toes in. Plant left foot approximately three feet in front of anchor point. Press suspended foot down into foot cradle. Lower hips into lunge position. Suspended leg will 
move back. Keep weight on heel of grounded foot. Press down on heel of grounded foot. - Hamstring Curl (hips lifted): Place heels in foot cradles directly under anchor point. Press down with heels into foot cradles. Lie on back with arms at sides and palms flat on ground. Use core and to lift hips. Draw heels toward hips while lifting hips and squeezing glutes.

3- Core Strength and Stability Drills

- High Back Extension: Grab the TRX handles and step back away from the anchor point while facing it, creating tension on the straps with palms facing down, hand close to shoulder. With feet shoulder-width apart, drop into a deep squat. Excel up out of the squat, pulling arm up to a "V" pattern.

- High Torso Rotation: Grasp onto the single TRX handle with an overlapping grip. Step forward until your body is at 45-degree angle, or close to. Rotate your torso by driving your hands to one side, while keeping your arms straight throughout. Return back to center position and rotate the opposite way.

- Kneeling Rollout: Kneels facing away from anchor. Hands on handles, body upright. Turn lower body to "10 o'clock" or "2 o'clock" position; upper body faces front. Slowly drive arms up and lean forward from knees, keeping core engaged. Return to start position, maintaining body alignment.

- Leg Raise: Lie face-up on the floor and grasp the handles above your chest. Raise your legs until the torso makes a 90degree angle with the legs. Rotate your hips to the right and lower your legs, keeping them together at all times. Stop before your legs reach the floor. At the bottom of your movement the back of your right hip should be on the floor and your toes should point to your right. Lift your legs back to the starting position, retracing their downward path.

- Suspended Pike from Hands: Adjust straps so that they are hanging about a 12 " to 18 " above the floor. With feet in the straps, get in the push-up position with abs lower back flat, and hands straight under shoulders. Pull your body upward thinking of bringing your feet toward your armpits, without bending your knees. Aim to get your core and rear aligned over your shoulders. With full control, lower body to starting position and repeat. 
- Suspended Pendulum: Place your feet in the handles and get into a push-up position. Swing your legs side to side while keeping your hips in line with the rest of your body.

-Suspended Side Plank with Reach Through: Lay on the floor and put your feet in the foot cradles. Move onto your right hip, support your upperbody with your right elbow and forearm. Straighten your legs so that you are in a side-plank position with your feet off the floor. Then lift your left hand toward the sky with your head looking toward the sky too. Next, bring the left hand underneath touching a point on the ground behind the elbow. Bring your left arm back upward to the sky again reaching as far as you can.

In our application process, we take into account that:

Focus should be on strengthening the upper and lower limb muscles; firming and strengthening core muscles

Table (3)

Significant differences between the averages (pre-test, post-test) in physical and skill variables of the study sample after the experiment $\mathrm{N}=\mathbf{1 5}$
- Stretching drills should be used at the end of each training drills to gain the full effects of stretching.

- Mixed methods are used; you can see high-intensity training Circuit training system.

- Circuit training includes (5) training, 8-12 reps. and 3-5 sets.

- Control of resistance training load and intensity through the change between time of performance and rest period between sets of a drills. appendix (2)

\section{Post Test measures:}

It was a post-test on, 25$29 / 03 / 2018$ in the same order to compare the pre-test, using statistical methods required.

Statistical Analysis:

Researcher used the processors the following statistics: (Mean - standard deviation - Median Coefficient of Skewness - TTest)

Results: 


\begin{tabular}{|c|c|c|c|c|c|c|c|}
\hline \multicolumn{8}{|l|}{ legs extensors } \\
\hline Quadrant jump & (Number.) & 5.00 & 0.760 & 7.750 & 0.856 & $55.00 \%$ & 10.12 \\
\hline $\begin{array}{l}\text { High jump } \\
\text { from stability }\end{array}$ & $(\mathrm{cm})$ & 52.66 & 2.350 & 76.333 & 1.914 & $31.00 \%$ & 29.23 \\
\hline Illinois agility & (sec.) & 12.761 & 0.558 & 11.530 & 0.249 & $-10.66 \%$ & 7.54 \\
\hline Accuracy kick & Degree & T.AI & $\because 77$ & $\varepsilon . Y T$ &.$r 9 V$ & $33.56 \%$ & 17.03 \\
\hline Kick timing & (sec.) & 0.357 & 0.012 & 0.278 & 0.011 & $-28.32 \%$ & 18.16 \\
\hline
\end{tabular}

T. Spreadsheet at $0.05=1.761$ when the degree of freedom $n-1=14$ Table (3) shows that there are statistically significant differences between the mean (pre-test and posttest) measurements of the study sample, with pre-test at the level (0.05) in all physical

\section{Table (4)}

variables and accuracy and kick timing, this is confirmed by the value of $(\mathrm{T})$ tabular, as well as in the rates of improvement where the rates of improvement ranged between $(10.66 \%-33.56 \%)$.

\section{Significant differences between the averages pre-test, post-test of the Biomechanical Variables during kicking for the research} sample. (Hip Joint) $N=15$

\begin{tabular}{|c|c|c|c|c|c|c|c|c|}
\hline \multirow{2}{*}{ Variables } & \multirow{2}{*}{$\begin{array}{c}\text { Unit of } \\
\text { measure }\end{array}$} & \multirow{2}{*}{$\begin{array}{c}\text { Stages of } \\
\text { skill }\end{array}$} & \multicolumn{2}{|c|}{ Pre-test } & \multicolumn{2}{|c|}{ Post test } & \multirow{2}{*}{ Percentage } & \multirow{2}{*}{$\begin{array}{c}\mathbf{T} \\
\text { value }\end{array}$} \\
\hline & & & Mean & Std. D & Mean & Std. D & & \\
\hline \multirow{3}{*}{$\begin{array}{l}\text { Result Angular } \\
\text { displacement } \\
(\theta)\end{array}$} & \multirow{3}{*}{ (Rad./s) } & backswing & 164.748 & 3.73739 & 174.104 & 1.04592 & $5.37 \%$ & 9.02 \\
\hline & & Impact & 123.66 & 3.5224 & 129.46 & 1.0982 & $4.48 \%$ & 5.88 \\
\hline & & Follow - up & 114.87 & 1.1721 & 117.96 & 1.0119 & $2.62 \%$ & 7.47 \\
\hline \multirow{3}{*}{$\begin{array}{l}\text { Result } \\
\text { displacement } \\
\left(\mathrm{S}^{\mathrm{R}}\right)\end{array}$} & \multirow[t]{3}{*}{ (m) } & backswing & 0.279 & 0.009 & 0.343 & 0.014 & $18.57 \%$ & 14.39 \\
\hline & & Impact & 0.2047 & 0.0031 & 0.266 & 0.0154 & $23.03 \%$ & 14.60 \\
\hline & & Follow - up & 0.2881 & 0.0153 & 0.3089 & 0.0251 & $6.71 \%$ & 2.65 \\
\hline \multirow{3}{*}{$\begin{array}{l}\text { Result } \\
\text { Angular } \\
\text { velocity }(\dot{\omega}) \\
\end{array}$} & \multirow[t]{3}{*}{ (Rad./s) } & backswing & -13.938 & 0.731 & -18.624 & 0.845 & $25.17 \%$ & 15.69 \\
\hline & & Impact & -0.366 & 0.013 & -0.558 & 0.028 & $34.32 \%$ & 23.27 \\
\hline & & Follow - up & -6.5966 & 1.03 & -7.7848 & 1.4798 & $15.26 \%$ & 2.47 \\
\hline \multirow{3}{*}{$\begin{array}{l}\text { Result Liner } \\
\text { velocity }\left(V^{R}\right)\end{array}$} & \multirow[t]{3}{*}{$(\mathrm{m} / \mathrm{s})$} & backswing & 1.182 & 0.062 & 2.090 & 0.099 & $43.44 \%$ & 29.08 \\
\hline & & Impact & 1.505 & 0.209 & 2.371 & 0.231 & $36.54 \%$ & 10.40 \\
\hline & & Follow - up & 0.6718 & 0.0714 & 0.932 & 0.2598 & $27.92 \%$ & 3.61 \\
\hline \multirow{3}{*}{$\begin{array}{l}\text { Result } \\
\text { acceleration } \\
\left(\mathrm{a}^{\mathrm{R}}\right)\end{array}$} & \multirow[t]{3}{*}{$\left(\mathrm{m} / \mathrm{s}^{2}\right)$} & backswing & 11.614 & 0.746 & 14.692 & 0.830 & $20.95 \%$ & 10.32 \\
\hline & & Impact & 11.128 & 0.642 & 13.871 & 0.431 & $19.78 \%$ & 13.27 \\
\hline & & Follow - up & 11.824 & 0.9872 & 14.534 & 1.211 & $18.65 \%$ & 6.49 \\
\hline \multirow{3}{*}{$\begin{array}{l}\text { Moment of } \\
\text { inertia (I) }\end{array}$} & \multirow{3}{*}{$\begin{array}{l}(\mathrm{Kg} . \\
\left.\mathrm{m} / \mathrm{s}^{2}\right)\end{array}$} & backswing & 0.050 & 0.007 & 0.051 & 0.006 & $1.30 \%$ & 0.41 \\
\hline & & Impact & 0.051 & 0.007 & 0.052 & 0.005 & $1.91 \%$ & 0.43 \\
\hline & & Follow - up & 0.0441 & 0.0133 & 0.0469 & 0.008 & $5.83 \%$ & 0.66 \\
\hline \multirow{3}{*}{$\begin{array}{l}\text { Angular } \\
\text { momentum } \\
\text { (L) }\end{array}$} & \multirow{3}{*}{$\begin{array}{l}(\mathrm{Kg} . \\
\left.\mathrm{rad} . / \mathrm{s}^{2}\right)\end{array}$} & backswing & -0.697 & 0.076 & -0.949 & 0.077 & $26.55 \%$ & 8.72 \\
\hline & & Impact & -0.018 & 0.002 & -0.029 & 0.005 & $37.93 \%$ & 7.64 \\
\hline & & Follow - up & -0.3134 & 0.0302 & -0.3795 & 0.0519 & $17.41 \%$ & 4.12 \\
\hline
\end{tabular}

T. Spreadsheet at $0.05=1.761$ when the degree of freedom $n-1=14$ 
Table (4) shows that there are statistically significant differences between the mean (pre-test and posttest) measurements of the study sample, with pre-test at the level (0.05) in measurements (Angular displacement - Result liner displacement - Angular

\section{Table (5)}

Significant differences between the averages pre-test, post-test of the Biomechanical Variables during kicking for the research sample. (Knee Joint) $\mathbf{N}=\mathbf{1 5}$

\begin{tabular}{|c|c|c|c|c|c|c|c|c|}
\hline \multirow{2}{*}{ Variables } & \multirow{2}{*}{$\begin{array}{c}\text { Unit of } \\
\text { measure }\end{array}$} & \multirow{2}{*}{$\begin{array}{c}\text { Stages of } \\
\text { skill }\end{array}$} & \multicolumn{2}{|c|}{ Pre-test } & \multicolumn{2}{|c|}{ Post test } & \multirow{2}{*}{ Percentage } & \multirow{2}{*}{$\begin{array}{c}\text { T } \\
\text { value }\end{array}$} \\
\hline & & & Mean & Std. D & Mean & Std. D & & \\
\hline \multirow{3}{*}{$\begin{array}{l}\text { Result Angular } \\
\text { displacement } \\
\text { ( } \theta)\end{array}$} & \multirow{3}{*}{ (Rad./s) } & backswing & 65.783 & 0.825 & 68.032 & 1.061 & $3.31 \%$ & 6.26 \\
\hline & & Impact & 109.37 & 0.958 & 113.35 & 0.843 & $3.51 \%$ & 11.67 \\
\hline & & Follow - up & 170.83 & 1.1693 & 176.71 & 1.0138 & $3 \%$ & 14.22 \\
\hline \multirow{3}{*}{$\begin{array}{l}\text { Result } \\
\text { displacement } \\
\left(\mathrm{S}^{\mathrm{R}}\right) \\
\end{array}$} & \multirow{3}{*}{ (m) } & backswing & 0.253 & 0.005 & 0.288 & 0.005 & $12.23 \%$ & 18.52 \\
\hline & & Impact & 0.244 & 0.011 & 0.282 & 0.011 & $13.44 \%$ & 9.14 \\
\hline & & Follow - up & 0.3581 & 0.0146 & 0.4097 & 0.0273 & $13 \%$ & 6.24 \\
\hline \multirow{3}{*}{$\begin{array}{l}\text { Result Angular } \\
\text { velocity } \\
\text { (ف) }\end{array}$} & \multirow{3}{*}{ (Rad./s) } & backswing & -1.963 & 0.042 & -2.472 & 0.102 & $20.59 \%$ & 17.27 \\
\hline & & Impact & 15.037 & 0.593 & 19.028 & 0.481 & $20.97 \%$ & 19.56 \\
\hline & & Follow - up & -0.286 & 0.0124 & -0.3712 & 0.0878 & $23 \%$ & 3.60 \\
\hline \multirow{3}{*}{$\begin{array}{l}\text { Result Liner } \\
\text { velocity } \\
\left(\mathrm{V}^{\mathrm{R}}\right)\end{array}$} & \multirow{3}{*}{$(\mathrm{m} / \mathrm{s})$} & backswing & 4.424 & 0.339 & 6.461 & 0.337 & $31.52 \%$ & 15.94 \\
\hline & & Impact & 1.905 & 0.112 & 2.451 & 0.191 & $22.27 \%$ & 9.23 \\
\hline & & Follow - up & 2.1813 & 0.0943 & 2.4596 & 0.0846 & $11 \%$ & 8.22 \\
\hline \multirow{3}{*}{$\begin{array}{l}\text { Result } \\
\text { acceleration } \\
\left(\mathrm{a}^{\mathrm{R}}\right)\end{array}$} & \multirow{3}{*}{$\left(\mathrm{m} / \mathrm{s}^{2}\right)$} & backswing & 52.014 & 3.479 & 55.22 & 1.217 & $5.82 \%$ & 3.25 \\
\hline & & Impact & 57.019 & 0.809 & 59.126 & 0.563 & $3.56 \%$ & 8.00 \\
\hline & & Follow - up & 31.977 & 0.8103 & 34.951 & 0.7654 & $9 \%$ & 9.98 \\
\hline \multirow{3}{*}{$\begin{array}{l}\text { Moment of } \\
\text { inertia } \\
\text { (I) }\end{array}$} & \multirow{3}{*}{$\begin{array}{l}(\mathrm{Kg} . \\
\left.\mathrm{m} / \mathrm{s}^{2}\right)\end{array}$} & backswing & 0.055 & 0.003 & 0.069 & 0.004 & $20.52 \%$ & 10.48 \\
\hline & & Impact & 0.068 & 0.003 & 0.075 & 0.003 & $9.32 \%$ & 6.17 \\
\hline & & Follow - up & 0.1584 & 0.0078 & 0.1687 & 0.0036 & $6 \%$ & 4.49 \\
\hline \multirow{3}{*}{$\begin{array}{l}\text { Angular } \\
\text { momentum } \\
\text { (L) }\end{array}$} & \multirow{3}{*}{$\begin{array}{c}(\mathrm{Kg} . \\
\left.\mathrm{rad} . / \mathrm{s}^{2}\right)\end{array}$} & backswing & -0.108 & 0.002 & -0.170 & 0.040 & $36.47 \%$ & 5.79 \\
\hline & & Impact & 1.022 & 0.009 & 1.427 & 0.061 & $29.06 \%$ & 24.58 \\
\hline & & Follow - up & -0.0525 & 0.0051 & -0.0731 & 0.0052 & $28 \%$ & 10.58 \\
\hline
\end{tabular}

T. Spreadsheet at $0.05=1.761$ when the degree of freedom $n-1=14$

Assiut Journal For Sport Science Arts velocity - Result Liner velocity - Result liner acceleration Angular momentum) and no the existence of significant differences in Moment of inertia, in Hip Joint, for the benefit of post-test, and improvement rates ranged between $(1.30 \%-43.44 \%)$. 
Table (5) shows that there are statistically significant differences between the mean (pre-test and posttest) measurements of the study sample, with pre-test at the level (0.05) in measurements (Angular displacement - Result liner displacement - Angular velocity - Result Liner velocity - Result liner acceleration Moment of inertia - Angular momentum) in Knee Joint, for the benefit of post-test, and improvement rates ranged between $(3.31 \%-36.47 \%)$.

\section{Table (6)}

\section{Significant differences between the averages pre-test, post-test of the Biomechanical Variables during kicking for the research} sample. (Ankle Joint) $\mathrm{N}=15$

\begin{tabular}{|c|c|c|c|c|c|c|c|c|}
\hline \multirow{2}{*}{ Variables } & \multirow{2}{*}{$\begin{array}{l}\text { Unit of } \\
\text { measure }\end{array}$} & \multirow{2}{*}{$\begin{array}{l}\text { Stages } \\
\text { of skill }\end{array}$} & \multicolumn{2}{|c|}{ Pre-test } & \multicolumn{2}{|c|}{ Post test } & \multirow{2}{*}{ Percentage } & \multirow{2}{*}{$\begin{array}{c}\mathbf{T} \\
\text { value }\end{array}$} \\
\hline & & & Mean & Std. D & Mean & Std. D & & \\
\hline \multirow{3}{*}{$\begin{array}{l}\text { Result } \\
\text { Angular } \\
\text { displacement } \\
(\theta) \\
\end{array}$} & \multirow{3}{*}{ (Rad./s) } & backswing & 151.69 & 0.6001 & 154.65 & 1.723 & $1.92 \%$ & 6.07 \\
\hline & & Impact & 130.83 & 1.4302 & 135.67 & 1.8772 & $3.56 \%$ & 7.67 \\
\hline & & Follow - up & 137.67 & 1.7623 & 142.43 & 3.3288 & $3 \%$ & 4.73 \\
\hline \multirow{3}{*}{$\begin{array}{l}\text { Result } \\
\text { displacement } \\
\left(\mathrm{S}^{\mathrm{R}}\right)\end{array}$} & \multirow{3}{*}{ (m) } & backswing & 0.3836 & 0.0104 & 0.4085 & 0.0011 & $6.09 \%$ & 8.91 \\
\hline & & Impact & 0.3991 & 0.0066 & 0.4271 & 0.0098 & $6.56 \%$ & 8.87 \\
\hline & & Follow - up & 0.6234 & 0.0556 & 0.6775 & 0.0319 & $8 \%$ & 3.16 \\
\hline \multirow{3}{*}{$\begin{array}{l}\text { Result } \\
\text { Angular } \\
\text { velocity }(\dot{\omega})\end{array}$} & \multirow{3}{*}{ (Rad./s) } & backswing & 3.7065 & 0.0983 & 4.7327 & 0.0867 & $21.68 \%$ & 29.29 \\
\hline & & Impact & 3.8997 & 0.1167 & 4.7047 & 0.143 & $17.11 \%$ & 16.32 \\
\hline & & Follow - up & 1.2021 & 0.1021 & 1.7695 & 0.0193 & $32 \%$ & 20.43 \\
\hline \multirow{3}{*}{$\begin{array}{l}\text { Result Liner } \\
\text { velocity }\left(V^{R}\right)\end{array}$} & \multirow{3}{*}{$(\mathrm{m} / \mathrm{s})$} & backswing & 5.1883 & 0.3184 & 6.4477 & 0.2134 & $19.53 \%$ & 12.29 \\
\hline & & Impact & 7.3569 & 0.2611 & 9.2753 & 0.2584 & $20.68 \%$ & 19.54 \\
\hline & & Follow - up & 2.4751 & 0.1643 & 3.6707 & 0.0681 & $33 \%$ & 25.15 \\
\hline \multirow{3}{*}{$\begin{array}{l}\text { Result } \\
\text { acceleration } \\
\left(a^{R}\right)\end{array}$} & \multirow{3}{*}{$\left(\mathrm{m} / \mathrm{s}^{2}\right)$} & backswing & 24.135 & 0.7759 & 28.144 & 1.0947 & $14.24 \%$ & 11.18 \\
\hline & & Impact & 125.81 & 1.0125 & 131.84 & 2.6054 & $4.57 \%$ & 8.07 \\
\hline & & Follow - up & 51.74 & 0.8859 & 55.797 & 1.9955 & $7 \%$ & 6.95 \\
\hline \multirow{3}{*}{$\begin{array}{l}\text { Moment of } \\
\text { inertia (I) }\end{array}$} & \multirow{3}{*}{$\begin{array}{l}(\mathrm{Kg} . \\
\left.\mathrm{m} / \mathrm{s}^{2}\right)\end{array}$} & backswing & 0.3853 & 0.0044 & 0.451 & 0.0244 & $14.58 \%$ & 9.91 \\
\hline & & Impact & 0.7993 & 0.0034 & 1.014 & 0.0653 & $21.18 \%$ & 12.29 \\
\hline & & Follow - up & 0.5691 & 0.0575 & 0.6618 & 0.0534 & $14 \%$ & 4.42 \\
\hline \multirow{3}{*}{$\begin{array}{l}\text { Angular } \\
\text { momentum } \\
\text { (L) }\end{array}$} & \multirow{3}{*}{$\begin{array}{l}(\mathrm{Kg} . \\
\left.\mathrm{rad} . / \mathrm{s}^{2}\right)\end{array}$} & backswing & 1.426 & 0.042 & 2.134 & 0.005 & $33.18 \%$ & 62.63 \\
\hline & & Impact & 3.115 & 0.004 & 4.769 & 0.021 & $34.55 \%$ & 189.50 \\
\hline & & Follow - up & 0.6665 & 0.0569 & 1.0669 & 0.098 & $38 \%$ & 13.22 \\
\hline
\end{tabular}

T. Spreadsheet at $0.05=1.761$ when the degree of freedom $n-1=14$

Table (6) shows that there are statistically significant differences between the mean (pre-test and posttest) measurements of the study sample, with pre-test at the level (0.05) in measurements (Angular displacement - Result liner displacement - Angular velocity - Result Liner velocity 
- Result liner acceleration Moment of inertia - Angular momentum) in Ankle Joint, for the benefit of post-test, and improvement rates ranged between $(1.92 \%-34.55 \%)$.

\section{Discussion:}

Study shows that there are statistically significant differences between the mean (pre-test and post-test) measurements of the study sample, with pre-test at the level (0.05) in all physical variables and accuracy and kick timing, this is confirmed by the value of $(\mathrm{T})$, indicated in Table ( $r$ ) where Static balance (3.632 s) Muscle strength for back extensors mean was (70 Kgf), Muscle strength for legs extensors mean was (131 Kgf), Quadrant jump test mean was (3.166 s), High jump from stability mean was $(76.33 \mathrm{~cm})$ Illinois agility mean was (11.530s), Accuracy kick mean was (4.833 Deg.) and Kick timing mean was $(0.278 \mathrm{~s})$.

researcher return this to the effectiveness of the functional resistance drills with elastic bands which have been applied using during the specific preparation phase of the training program for kicking performance for soccer junior, As indicated in Table $\left({ }^{\top}\right)$, mean scores across all items showed the positive effect of functional resistance Drills with elastic bands that are completely consistent with those obtained by (Tiana Weiss, et al., 2010) (23) As functional resistance training becomes a more popular method to improve muscular fitness, and has been considered to be a better alternative than traditional resistance training for improving various measures of muscular fitness including strength, endurance, coordination and balance. In addition, it may be possible to maintain or enhance flexibility through functional resistance training due to the nature of the drills (multi-joint with focus on full range of motion), therefore (Vom Hofe,1995) mentions that the functional strength drills suit all individuals with different levels and aims to improve the relationship between the muscles and the nervous system. And Michelle Boyle (2004) (16) said that Functional training programs lead to improve muscle strength, neuromuscular control, integration of motor and speed-strength. as well as Table $(r)$ shows that rates of improvement where the rates of improvement ranged 
between $(10.66 \%-33.56 \%)$.

The highest value to percentage of improvement was Accuracy kick 33.56\% followed by High jump from stability of $31.00 \%$ and $27.75 \%$ static balance. the researcher believes that is very logical in terms of performance of the skill of good soccer players. Since the Accuracy kick, which reached its highest value at all is the outcome of the economy in the effort represented in the Fast Force (power), and balance the skill during the performance proper, as the functional resistance training has helped in the development of strength of the legs muscles, which is ranked fourth on the value of $22.72 \%$, Where researchers saw that the instep kick in soccer require multiple amounts of power to complete the motor task of kicking, and must regulate the force exerted and good distribution and direct them to lead to the production of kinetic energy, as well as in turn lead to successful motor performance, and this contributed to the functional strength training. Those results agree with studies for Chek, Paul (2001) (3), Christine Cunningham (2000) (5), Fabio comana
(2004) (9), Ron Jones (2003) (21), Scott Gaines (2003) (22). Table ( $\varepsilon$ ) shows that there are statistically significant differences for benefit of pretest at the level (0.05) in Biomechanical Variables during kicking for the research sample. (Hip Joint) The average angular displacement $\left(174^{\circ}\right)$, linear displacement $(0.343 \mathrm{~m})$, angular velocity $(18.624 \%$ s) and acceleration $(14.692 \mathrm{~m} / \mathrm{s})$, angular movement $\left(0.949 \mathrm{~kg} . \mathrm{m} .{ }^{\circ} / \mathrm{s}^{2}\right)$ in backswing phase, the linear velocity $(2.371 \mathrm{~m} / \mathrm{s})$ was recorded Impact phase for kick soccer, while there was no significant difference in moment of inertia where the calculated $(\mathrm{T})$ value was lower than Spreadsheet $(\mathrm{T})$ value at \pm 1.761 (critical value of significance). researcher return this to the effectiveness of the functional resistance drills with elastic bands which have been applied using during the specific preparation phase of the study sample to improve the level of performance and biomechanical variables, as it works to increase the strength of the lower limb muscles and core muscles and this is consistent with what was mentioned (Wallace, BJ,et al., (2006) (25) Elastic bands offer 
variable resistance throughout a range of motion and their incorporation with drills movements has long been used for rehabilitation purposes. More recently, however, elastic bands have found a niche in many strength programs because of the purported performance benefits.

as well as Table ( $\Sigma$ ) shows that rates of improvement where the rates of improvement ranged between $(1.30 \%$ $43.44 \%)$. The highest value to percentage of improvement was linear velocity $43.44 \%$, angular movement $37 \%$, angular velocity $34.32 \%$, linear displacement $23.03 \%$ and acceleration $20.95 \%$, while the lowest in angular displacement was $5.37 \%$, followed by moment of inertia was the lowest $1.91 \%$ because there is no significant difference between the pre and post measurements,

the researcher was believed that when the hip returned to back in the moment of maximum back swing that will achieving the objective of this stage, which add a large amount of angular momentum to the movement of instep kick. It also allows an increase in the time of maximum back swing, giving greater preference to impulse for a strong instep kick, that is through the use of law mechanical, (impulse = force $x$ time), thereby increasing the lead time to increase the final product, those results agree with Jin Wang, Mike Griffin (1997) (12), and Michael Boyle (2004) (17) said that the functional drills programs lead to improve muscle strength, control neuromuscular, integration of motor and speed-strength.

Table ( $\left.{ }^{0}\right)$ shows that rates of improvement where the rates of improvement ranged between $(3.31 \%$ $36.47 \%)$. The highest value to percentage of improvement was linear velocity $31.52 \%$, angular movement $36.47 \%$, angular velocity $20.97 \%$, moment of inertia $20.52 \%$, linear displacement $13.44 \%$, while the lowest in acceleration $5.82 \%$, followed by angular displacement was the lowest $3.31 \%$, as well as Table ( $\left.{ }^{\circ}\right)$ shows that there are statistically significant differences for benefit of pretest at the level (0.05) in Biomechanical Variables during kicking for the research sample. (Knee Joint) The average angular displacement $\left(113^{\circ}\right)$, linear displacement $(0.282 \mathrm{~m})$, angular velocity

\section{Assiut Journal For Sport Science Arts}


$(19.028 \%$ s) and acceleration $(59.12 \mathrm{~m} / \mathrm{s})$, angular movement $\left(1.427 \mathrm{~kg} . \mathrm{m} .{ }^{\circ} / \mathrm{s}^{2}\right)$, moment of inertia $\left(0.075 \mathrm{~kg} . \mathrm{m} / \mathrm{s}^{2}\right)$ in Impact phase, while the linear velocity $(6.461 \mathrm{~m} / \mathrm{s})$ was recorded in backswing phase, researcher return this to the effectiveness of the functional resistance drills with elastic bands which have been applied using during the specific preparation phase of the study sample to improve the level of performance and biomechanical variables,

the researcher was believed that moment of impact begins the hip deactivation speed the amount of horizontal movement to begin to move into angular displacement of the knee joint, this agree with Barfield, B (1998) (1) Using EMG measurements, found maximal activity of hip and knee muscles during the terminal stage of the backswing phase which increased again prior to ball impact. With activity levels were higher for all muscles throughout the kick whereas a proximal-to-distal sequence of muscle activation was not evident. From the above descriptions, it becomes clear that the rapid knee flexion and extension is an important aspect of soccer kick performance. Therefore, De Proft et al. (1988) (7) opinion that this movement is accompanied by a stretch of the knee extensor musculature during backswing followed by immediate shortening during forward shank movement. It has been shown that kicking speed is significantly higher when the knee extensor musculature is stretched and then shorten compared with kicks involving only concentric actions. This is consistent with Tiana Weiss, et al., (2010) (23) that functional resistance drills it may be possible to maintain or enhance flexibility through functional resistance training due to the nature of the drills (multi-joint with focus on full range of motion).

Table (7) shows that rates of improvement where the rates of improvement ranged between $(1.92 \%$ $34.55 \%$ ). The highest value to percentage of improvement was angular movement $34.55 \%$, angular velocity $21.68 \%$, linear velocity $20.68 \%$, moment of inertia $21.18 \%$, acceleration $14.24 \%$, while the lowest in linear displacement $6.56 \%$, followed by angular displacement was the lowest $3.56 \%$, as well as Assiut Journal For Sport Science Arts 
Table ( 7 ) shows that there are statistically significant differences for benefit of pretest at the level (0.05) in Biomechanical Variables during kicking for the research sample. (Knee Joint) The average linear displacement $(0.427 \mathrm{~m})$, linear velocity $(9.275 \mathrm{~m} / \mathrm{s}), \quad$ acceleration $(131.84 \mathrm{~m} / \mathrm{s})$, angular movement $\left(4.769 \mathrm{~kg} . \mathrm{m} . \% \mathrm{~s}^{2}\right)$, and moment of inertia (1.014 $\mathrm{kg} . \mathrm{m} / \mathrm{s}^{2}$ ), in Impact phase, while the angular displacement $\left(154^{\circ}\right)$ angular velocity $(4.732 \%)$ was recorded in backswing phase, researcher return this to the effectiveness of the functional resistance drills with elastic bands which have been applied using during the specific preparation phase of the study sample to improve the level of performance and biomechanical variables, The researcher believed that Soccer kick is characterized by segmental and joint rotations in multiple planes, and instep kick one of the movements that belong to the open kinetic chains which aimed at producing high angular velocity of the feet through profile kinematic for segments to various body involved in the performance. This agree with Manolopoulos., E. et. all
(2006) (15) Masuda, K., et. all. (2005) (16) In impact phase, the thigh angular velocity is almost zero while the shank and the foot reach peak angular velocity.

\section{Conclusions:}

Within the scope of the objectives, hypotheses, procedures, and results, the researcher reached the following:

* Functional resistance training using elastic bands has improved maximum strength and muscle capacity of the two men.

* Functional resistance training using elastic bands has improved values of the biomechanical variables under study in post-test.

* Functional resistance training using elastic bands has improved performance of kicking in front of the front foot on goal.

* Functional resistance training using elastic bands led to kinetic bonding between the leg joints (Hip- Knee- Ankle) while kicking performance.

\section{Recommendations:}

- Using functional resistance drills with elastic bands within training programs of thrower.

- Diversity in the application of functional resistance drills with elastic bands for upper and 
lower extremities and core muscles because of its positive impact on technical performance.

- The need for power measurements of upper and lower extremities, core muscles, balance and analysis motion, as well as working on improving them during different training periods.

- The use of functional resistance exercises using elastic bands within training programs for soccer players, for their role in improving the various fitness elements, as follows: Muscle strength for back extensors, Muscle strength for legs extensors, Quadrant jump, High jump from stability, Illinois agility, beside (core muscles).

- Diversity in the application of functional resistance exercises using rubber elastic, especially for the muscles of the lower limb and center muscles (core muscles) because of its positive impact on technical performance in soccer.

- The need to perform strength measurements of the muscles of the lower limb and center stabilization muscles (core muscles) and static and movie balance, as well as conduct kinetic analysis of the various skills and work to improve them during training periods

\section{References:}

1- Barfield, B (1998): The biomechanics of kicking in soccer,Clinicsin Sports Medicine,17(4): 711.728

2- Bernardo Requena, Juan Jose, Eduardo Saez, Jaan Ereline, Inmaculada Garci, Helena Gapeyeva, and Matipa A. Suke (2009): Functional Performance, Maximal Strength, and Power Characteristics in Isometric and Dynamic Actions of Lower Extremities in Soccer Players, The Journal of Strength and Conditioning Research 23(5):1391-401

3- Chek, Paul, (2001): Big Bang Exercise, IDEA Fitness Edge, pp 8-10

4- Christou A. Marios, Ilias smilios, Knostantinos sotiropoulos, Knostantinos volaklis, Theofilos pilianidis, and Savvas p. Tokmakidis (2006): The Effects of resistance training on the physical capacities of adolescent soccer players, The Journal of Strength and Conditioning Research 20(4):783-91.

5- Christine Cunningham (2000): The Importance of Functional Strength Training, Personal Fitness Professional 
magazine, American Council on Exercise publication, April.

6- Dave Schmitz (2003): Functional Training Pyramids, New Truer High School, Kinetic Wellness Department, USA

7- De Proft E, Cabri J, Dufour W, Clarys J. (1988): Strength training and kick performance in soccer players. In: Reilly T, Lees A, Davids K, Murphy WJ, eds. Science and football. London: $\mathrm{E}$ \& FN Spon, 1988a: 109-113.

8- Emad Ahmed Al-Nadi (2013): Effectiveness of legislation training lowed according to season period from some compounds athletic fitness for football players

9- Fabio Comana (2004): function training for sports, Human Kinetics: Champaign IL, England, pp27.

10- Hamada A. Habib \& Hossam Hussein (2010): Effectiveness of strength functional training on some physical and biomechanical parameters affecting instep kick for soccer junior, The $13^{\text {th }}$ International Scientific Conference Physical Education $\&$ Sport Challenges of the $3^{\text {rd }}$ Millennium" Faculty of physical Education for men, Helwan University, Cairo, Egypt.
11- J Helgerud, Gil Rodas, O J Kemi, and J Hoff (2011): Strength and Endurance in Elite Football Players, International Journal of Sports Medicine 32(9):677-82

12- Jin Wang, Mike Griffin (1997): Kinematic Analysis of the soccer curve Ball shot, National strength \& conditioning Association, vol 19, No 1,54:55 February

13- Khaled W. Ibrahim (2014): Effect of functional resistance Drills with Elastic bands on performance of Release Phase in Shot Put Competition, Theories \& Applications, The International Edition, Faculty of Sport Education, Abo Qir, Alex. University.

14- Lees, A. \& Nolan, L. (1998). The Biomechanics of soccer; a review. Journal of sport science, 16: 211-234

15- Manolopoulos, E., C. Papadopoulos, E. Kellis (2006): Effects of combined strength and kick coordination training on soccer kick biomechanics in amateur players. Scandinavian Journal of Medicine \& Science in Sports, vol.16, Issue2, 102-110 16- Masuda, K., Kikuhara, N., Demura, S., Katsuta, S. \& Yamanaka, K. (2005): Relationship between muscle 
strength in various isokinetic movements and kick performance among soccer players. J. sports med. Phys. fitness, 45, 44-52

17- Michael Boyle (2004): Functional Balance Training Using a Domed Device, j Spine, 21, pp2640-2650

18- Mohamed Hassan Allawi, Mohamed Nasr Radwan 1994: motor performance tests, 3rd edition, Dar al-Fikr alArabi, Cairo.

19- Mohamed Sobhy Hassanein 2001: Measurement and Evaluation in Physical Education and Sports, Part 1, 4th edition, Dar Al Fikr Al Arabi, Cairo.

20- Opavsky, P. (1988): An investigation of linear and angular kinematics of the leg during two types of soccer kick. In: Science and Football. Eds: Reilly, T., Lees, A., Davids, K. and Murphy, W.J. London: E \& FN Spon. 456459.

21- Ron Jones (2003): Functional Training1: Introduction, Reebo Santana, Jose Carlos Uni., USA
22- Scott Gaines (2003):

Benefits and Limitations of Functional Exercise, Vertex Fitness, NESTA, USA.

23- Tiana Weiss, Jerica Kreitinger, Hilary Wilde, Chris Wiora, Michelle Steege Lance Dalleck, Jeffrey Janet., (2010): Effect of Functional Resistance Training on Muscular Fitness Outcomes in Young Adults, J Exerc Sci Fit. Vol 8. No 2. pp 113-122.

24- Vom Hofe, A. (1995): The problem of skill specificity in complex athletic tasks: A revisitation. International Journal of Sport Psychology 26, pp249-261.

25- Wallace, BJ, Winchester, JB, and McGoogan, MR., (2006): Effects of elastic bands on force and power characteristics during the back squat drills. Journal of Strength Condation Resistance, 20: pp 268-272.

26- Weineck, J. (1992). Optimales Fußballtraining. Teil 1: Konditionstraining des Fußballspielers. PERIMED spitta, Medizin. Verlagsges., Nürnberg. 